\title{
Modulatory effect of chrysin against acrylamide-induced neurotoxicity in rats
}

\author{
Somaya Z. Mansour ${ }^{1}$, Eman I. kandil ${ }^{2}$, Doaa H. Abdel-Gawad ${ }^{2 *}$ and Fatma S. M. Moawed ${ }^{1}$ \\ ${ }^{1}$ National Centre of Radiation Research and Technology (NCRRT), Atomic Energy Authority (AEA), \\ ${ }^{2}$ Biochemistry Department, Faculty of Science, Ain shams University
}

\section{A R T I C L E I N F O}

Article history:

Received 26 January 2017

Accepted 22 March 2017

Keywords:

Acrylamide;

Neurotoxicity;

Chrysin;

$\beta$-amyloid;

$B D N F$;

Caspase-3.

\begin{abstract}
A B S T R A C T
The main objective of the current study is to recapitulate the neuroprotective role of chrysin on acrylamide-induced neurotoxicity in rats. Fifty Wister albino rats were divided into five groups served as control, group treated orally with 50 $\mathrm{mg} / \mathrm{kg}$ b.wt of chrysin daily for 21days (negative control group), group treated orally with Acrylamide (ACR) $25 \mathrm{mg} / \mathrm{kg}$ for 21 days (positive control group), group treated orally with chrysin parallel with ACR administration (protective group) and group exposed to ACR then treated with chrysin (therapeutic group). As compared to the control group, daily oral administration of ACR induced a significant decrease in serum activity of creatinine kinase-BB (CK-BB) and levels of catecholamine and brain derived neurotrophic factor (BDNF) in brain tissue. Moreover, the levels of serum interleukine-6 (IL-6) and brain levels of malondialdhyde (MDA), $\beta$-amyloid, acetylcholinestrase (AChE) and caspase-3 were remarkably augmented in ACR-induced rats. Chrysin has a potent antioxidant and anti-inflammatory activities that act against acrylamide neurotoxicity. It minimized the levels of MDA, IL-6, $\beta$-amyloid, AChE and remarkably antagonized the decreasing effect of ACR on catecholamines, CK-BB and BDNF compared to the positive control group. Histopathological investigation of brain tissues after treatment partially supported the beneficial effect of chrysin. From the obtained results, it can be concluded that the chrysin has neuroprotective and therapeutic effect against acrylamide inducedneurotoxicity.
\end{abstract}

\section{Introduction}

Acrylamide (ACR) is a low molecular weight, water soluble vinyl monomer from which polyacrylamides are synthesized to be used in the personal care and grooming products, such as lotions, cosmetics and deodorants ${ }^{[1]}$. It is commonly used in industries and laboratories. The industrial application of acrylamide is associated with pollution and health risks; it has been reported to be present in plant material like potatoes, carrots, radish, lettuce, Chinese cabbage, parsley, onions, spinach and rice paddy in sugar and olives ${ }^{[2]}$.

The major health concerns associated with ACR are due to its various sources and methods of exposure as in drinking water, inhalation, skin absorption and occupational exposure. Direct exposure to acrylamide may result from ingestion of high-carbohydrate foods prepared at high temperatures such as potato crisps, crackers and French fries. Indirect exposure may result

* Corresponding author.

E-mail address: the_princeca@yahoo.com from residual traces of the monomer in food packaging where polyacrylamide is used as a binding agent ${ }^{[3]}$. Acrylamide has been reported to be neurotoxic, toxic to the reproductive system and carcinogenic in experimental animals ${ }^{[4]}$. Although the polymer is nontoxic, occupational exposure of humans and experimental intoxication of laboratory animals with the monomeric form produces a neurotoxic syndrome characterized by ataxia, skeletal muscle weakness and weight loss ${ }^{[5]}$.

Chrysin (5, 7-dihydroxyflavone) is a natural flavonoid presented in many plant extracts including blue passion flower (Passiflora caerulea) and honey. Similar to other flavonoids, chrysin has many pharmacological effects, including anticancer, anti-inflammatory, anti-neurotoxic, antioxidant ${ }^{[6]}$ and anti-hypertensive ${ }^{[7]}$ effects. Mehri et al. ${ }^{[8]}$ and Yoa et al. ${ }^{[9]}$ suggested that chrysin could be used as a neuroprotective agent in different models.

The main objective of the research is to study the effect of chrysin as anto-oxidant and anti-inflammatory agent 
on the acrylamide induced neurotoxicity of male wister rats.

\section{Materials and methods}

\section{Chemicals and reagents}

Acrylamide and chrysin were obtained from Sigma Chemical Co., St. Louis, Mo. USA. All other chemicals and reagents were of analytical grade.

\section{Experimental animals:}

Adult male Wister rats weighing about 120-150 g purchased from the breeding unit of the El-Nile Co. for Pharmaceuticals and Chemical Industries (Egypt). The animals were maintained on a commercial standard pellet diet and tap water ad libitum. Animals' maintenance and treatments were conducted in accordance with the National Institute of Health Guide for Animal, as approved by Institutional Animal Care and Use Committee (IACUC).

\section{Experimental design}

Fifty animals were randomly divided into five equal groups as follows:

Group 1 (Normal control): Rats served as normal control.

Group 2 (ACR/Positive control): Acrylamide was dissolved in saline solution and administrated orally by gavage ( $25 \mathrm{mg} / \mathrm{kg}$ b.wt daily for 21 days) according to Lopachin et al. ${ }^{[7]}$

Group 3 (Chrysin/Negative control): Chrysin was dissolved in saline solution and administrated orally by gavage $(50 \mathrm{mg} / \mathrm{kg}$ b.wt daily for 21 day) according to Mehri et al. ${ }^{[8]}$

Group 4 (protective group) (Chrysin+ACR): Rats were orally treated with ACR as in group 2 for 21 days parallel with chrysin as in group 3

Group 5 (therapeutic group) (ACR + Chrysin): Rats were orally treated with ACR as in group 2 for 21 days then chrysin were orally administrated as in group 3 for another 21 days.

All animals were sacrificed at the end of the experiment under anesthesia by light ether after fasted over night; blood samples were collected in centrifuge tubes and centrifuged at $3000 \mathrm{rpm}$ for $20 \mathrm{~min}$. Serum samples were stored at $-20^{\circ} \mathrm{C}$ until used for biochemical assays. The whole brain tissues was excised rapidly washed in ice cold saline, wiped dry with a filter paper and weighed for the biochemical analysis. The brain were separated out and divided into two parts, the first part was weighed to prepare a $10 \%(\mathrm{w} / \mathrm{v})$ tissue homogenate was prepared in $0.1 \mathrm{M}$ phosphate buffer $(\mathrm{pH}$ 7.4). The homogenates were centrifuged at $10,000 \mathrm{~g}$ for $15 \mathrm{~min}$ and aliquots of supernatants were separated and used for the different biochemical assays. The second part was used for histopathological examination.

\section{Biochemical assays}

Malondialdehyde level (MDA) was determined colormetrically in brain tissue according to Yoshioka et al., ${ }^{[10]}$. Acetylcholinesterase (AchE) was determined in brain tissue by kinetic method. Brain levels of $\beta$ amyloid, interleukin-6 (IL-6), brain derived neurotrophic factor (BDNF), Caspase-3 activity and serum activity of creatinine kinase $\mathrm{BB}$ isoenzyme (CK-BB) were determined by ELISA technique using reagents provided by my Biosource Inc. U.S.A. Serotonine (SER) , epinephrine (EPI) and norepinephrine (NE), were determined in brain tissue by fluorometeric method according to Ciarlone ${ }^{[11]}$.

\section{Histopathological study}

Following rats sacrificing, the brain were rapidly dissected and excised, rinsed in saline solution and cut into suitable pieces which were fixed in neutral buffered formalin $(10 \%)$ for 24 hours. Following fixation, the specimens were dehydrated in ascending series of alcohol (methyl, ethyl and absolute ethyl), cleared in xylene then embedded in paraffin at $60^{\circ} \mathrm{C}$. Section of 5 microns thickness were cut and stained with haematoxylin and eosin according to method adopted by Banchroft et al., ${ }^{[12]}$ and examined by light microscope for histopathological investigation.

\section{Statistical analysis}

All statistical analyses were conducted by using the statistical package for windows version 15.0 (SPSS Software, Chicago, IL). The results for continuous variables were expressed as mean \pm standard error. Values were compared by one-way analysis of variance (ANOVA). Post-hoc testing was performed for intergroup comparisons using the least significant difference (LSD) test, and $\mathrm{p}<0.05$ was considered statistically significant.

\section{Results:}

The brain levels of MDA, AchE and $\beta$-Amyloid in Table (1) exhibited a significant increase in groups of ACR, Chrysin + ACR and ACR + Chrysin $(722 \%$; $\mathrm{P} 1<0.0001$, $55 \% ; \quad \mathrm{P} 2<0.023 \quad \& \quad 202 \% ; \quad \mathrm{P} 1<0.0001), \quad(163 \%$; $\mathrm{P} 1<0.0001,139 \%$; $\mathrm{P} 1<0.0001 \& 50 \%$; $\mathrm{P} 1<0.0001)$ and (717\%; $\quad \mathrm{P} 1<0.0001, \quad 537 \% ; \quad \mathrm{P} 1<0.0001 \& 336 \%$; $\mathrm{P} 1<0.0001)$ respectively compared to the control group, administration of chrysin in the protective and therapeutic groups ameliorated the elevation of MDA, AchE and $\beta$-amyloid in respect to ACR group.

As shown in Fig. 1 the serum level of IL-6 had significantly increased upon administration of acrylamide in ACR, CHR+ACR and ACR+CHR groups (212\%; P1< 0.0001， 86\%; P1<0.0001\& 109\%; $\mathrm{P} 1<0.0001)$ respectively, while the activity of serum CK -BB was significantly declined (-79\%; P1<0.0001,-31\%; $\mathrm{P} 1<0.0001$ and $-25 \% ; \mathrm{P} 1<0.0001)$ respectively compared with the control group. Administration of chrysin significantly improved the alteration induced by acrylamide in IL-6 and CK-BB levels in both protective and therapeutic groups.

Administration of animals to ACR result in a significant increase in the activity of caspase- 3 in rats brain of ACR, Chrysin + ACR and ACR + Chrysin groups $(870 \%$; $\mathrm{P} 1<0.0001,412 \%$; $\mathrm{P} 1<0.0001 \& 311 \%$; $\mathrm{P} 1<0.0001)$ respectively compared to its corresponding control values, whereas the levels of epinephrine, norepinephrine, serotonin and BDNF in brain tissue showed 
significant decreases in ACR and ACR+CHR groups ($40 \%$; $\mathrm{P} 1<0.0001,-11 \%$; $\mathrm{P} 1<0.031)$ for epinephrine and ACR , CHR+ACR and ACR+CHR groups $(-28 \%$; $\mathrm{P} 1<$ $0.0001,-20 \%$; P1<0.0001\&-19\% ; P1<0.0001), (-75\%; $\mathrm{P} 1<0.001,-26 \% ; \mathrm{P} 1<0.045 \&-43 \%$; $\mathrm{P} 1<0.0007)$ and $(-$ $39 \%$; $\mathrm{P} 1<0.0001,-14 \%$; $\mathrm{P} 1<0.002 \&-26 \%$; $\mathrm{P} 1<0.0001)$ for nor-epinephrine, serotonin and BDNF respectively.
Treatment with chrysin post ACR exposure (therapeutic group) suppressed the elevation in caspase- 3 activity in respect to control group. Additionally, the administration of chrysin parallel to ACR (protective group) significantly increased the brain levels of epinephrine, nor-epinephrine, serotonin and BDNF (Table 2).

Table (1): Brain levels of MDA, AchE, and $\beta$-Amyloid of rats in the different studied groups.

\begin{tabular}{||l||c|c|c||}
\hline \multicolumn{1}{|c||}{ Proups } & $\begin{array}{c}\text { MDA } \\
\text { (nmol/g tissue) }\end{array}$ & $\begin{array}{c}\text { AchE } \\
\text { (u/mg tissue) }\end{array}$ & $\begin{array}{c}\text { B-Amyloid } \\
\text { (pg/mg tissue) }\end{array}$ \\
\hline Normal control & $1.18 \pm 0.08^{\text {bde }}$ & $15.7 \pm 0.53^{\text {bcde }}$ & $4.92 \pm 0.79^{\text {bcd }}$ \\
\hline $\begin{array}{l}\text { ACR } \\
\text { (Positive control } \\
\text { group) } \\
\text { \% Change }\end{array}$ & $9.7 \pm 0.85^{\text {acde }}$ & $41 \pm 0.95^{\text {acde }}$ & $40.2 \pm 8.98^{\text {acde }}$ \\
\hline $\begin{array}{l}\text { Chrysin } \\
\text { (Negative control } \\
\text { group) }\end{array}$ & $1.4 \pm 0.07^{\text {be }}$ & $19.9 \pm 1.94^{\text {abde }}$ & $717 \%$ \\
\hline $\begin{array}{l}\text { Change } \\
\text { Chrysin + ACR } \\
\text { (Protective group) } \\
\text { \% Change }\end{array}$ & $1.83 \pm 0.16^{\text {abe }}$ & $23.5 \pm 1.52^{\text {abcd }}$ & $21.4 \pm 0.81^{\text {abce }}$ \\
\hline $\begin{array}{l}\text { ACR + Chrysin } \\
\text { (Therapeutic } \\
\text { group) } \\
\text { \% Change }\end{array}$ & $3.56 \pm 0.32^{\text {abcd }}$ & $37 \pm 0.6^{\text {abce }}$ & $31.3 \pm 2.2^{\text {abcd }}$ \\
\hline
\end{tabular}

Each value represents mean $\pm \mathrm{SD},{ }^{\mathrm{a}}$ Significance $v s$. control group, ${ }^{\mathrm{b}}$ Significance $v s$. ACR group, ${ }^{\mathrm{c}}$ significant $v s$. chrysin , ${ }^{\mathrm{d}}$ significant $v s$. chrysin + ACR group,${ }^{\mathrm{e}}$ significant $v s$. ACR + chrysin group.

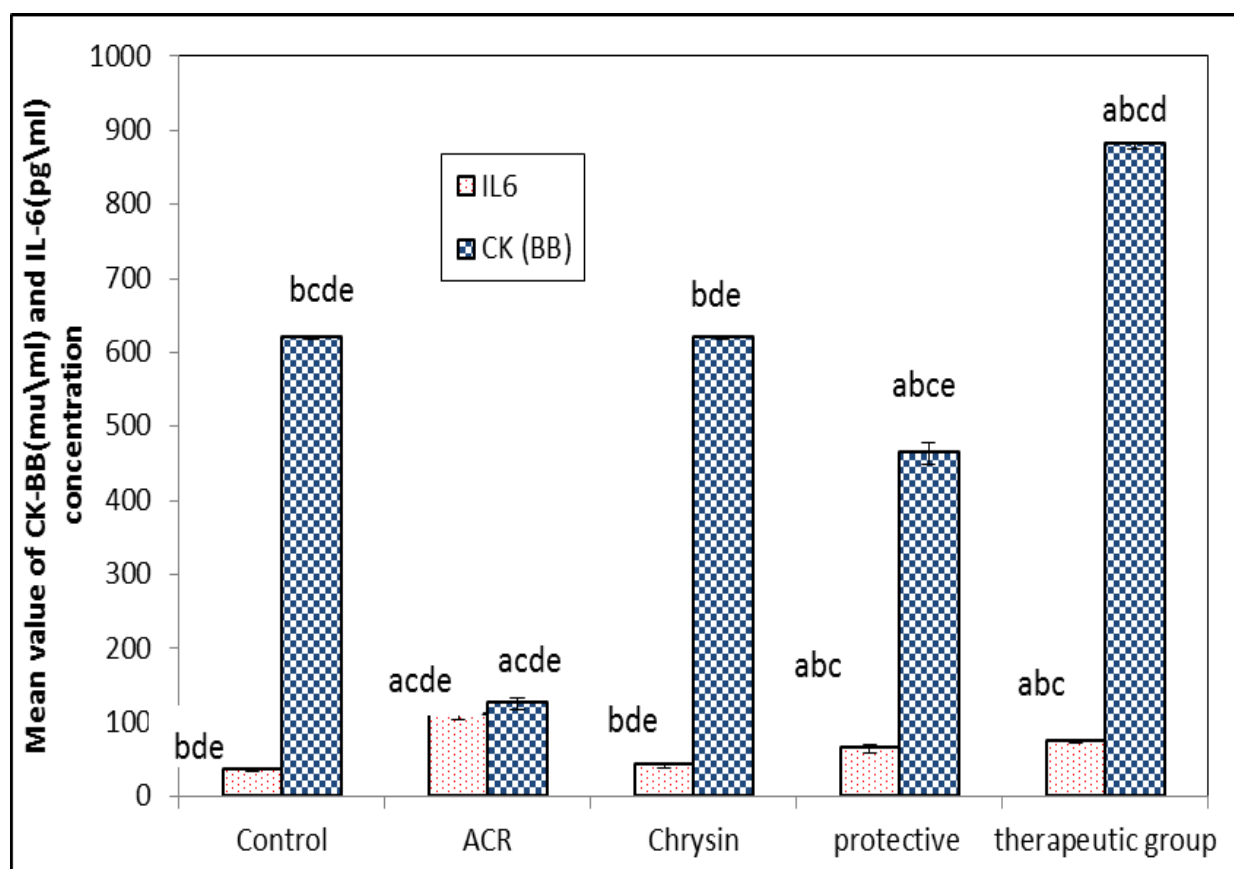

Fig (1): The effect of acrylamide on both CK-BB and IL-6. Each value represents mean $\pm \mathrm{SD},{ }^{\mathrm{a}}$ Significance $v s$. control group, ${ }^{\mathrm{b}}$ Significance $v s$. ACR group, ${ }^{\mathrm{c}}$ significant $v s$. chrysin, ${ }^{\mathrm{d}}$ significant $v s$. chrysin + ACR group, ${ }^{\mathrm{e}}$ significant $v s$. ACR + chrysin group. 
Table (2): Brain activity of caspase-3 and EPI, NE, SER and BDNF levels of rats in the different studied groups.

\begin{tabular}{|c|c|c|c|c|c|}
\hline Parame & $\begin{array}{c}\text { Caspase-3 } \\
\text { (U/ml) }\end{array}$ & $\begin{array}{c}\text { EPI } \\
(\text { ng/g wet tissue) }\end{array}$ & $\begin{array}{c}\text { NE } \\
\text { (ng/g wet tissue) }\end{array}$ & $\begin{array}{c}\text { SER } \\
\text { (ng/g wet tissue) }\end{array}$ & $\begin{array}{l}\text { BDNF } \\
\text { (ng/mg) }\end{array}$ \\
\hline Normal control & $1.01 \pm 0.01^{\text {bde }}$ & $72.05 \pm 4.31^{\text {bde }}$ & $881.65 \pm 23.55^{\text {bcde }}$ & $16.65 \pm 2.05^{\text {bde }}$ & $130 \pm 6.79^{\text {bde }}$ \\
\hline $\begin{array}{l}\text { ACR } \\
\text { (Positive control } \\
\text { group) } \\
\% \text { Change }\end{array}$ & $9.80 \pm 2.33^{\text {acde }}$ & $43.1 \pm 2.97^{\text {acde }}$ & $632.4 \pm 10.75^{\text {acde }}$ & $4.12 \pm 0.106^{\text {acde }}$ & $\begin{array}{c}78.8 \pm 2.12^{\text {acde }} \\
-39 \% \\
\end{array}$ \\
\hline $\begin{array}{l}\text { Chrysin } \\
\text { (Negative control } \\
\text { group) } \\
\% \text { Change }\end{array}$ & $\begin{array}{c}2.30 \pm 0.49^{\text {bde }} \\
128 \%\end{array}$ & $\begin{array}{c}71.1 \pm 1.27^{\text {be }} \\
-1.3 \%\end{array}$ & $\begin{array}{c}842.5 \pm 10.6^{\text {bde }} \\
-4.4 \%\end{array}$ & $\begin{array}{c}14.8 \pm 2.54^{\text {be }} \\
-11 \%\end{array}$ & $\begin{array}{c}130.15 \pm 1.2^{\text {bde }} \\
0.11 \%\end{array}$ \\
\hline $\begin{array}{l}\text { Chrysin + ACR } \\
\text { (Protective } \\
\text { group) } \\
\text { \% Change }\end{array}$ & $\begin{array}{c}4.15 \pm 1.24^{\mathrm{abc}} \\
412 \%\end{array}$ & $66.6 \pm 0.84^{b}$ & $\begin{array}{c}707.45 \pm 19.86^{\mathrm{abc}} \\
-20 \%\end{array}$ & $\begin{array}{c}12.35 \pm 0.495^{\mathrm{ab}} \\
-26 \%\end{array}$ & $\begin{array}{c}111.45 \pm 1.34^{\text {abce }} \\
-14 \%\end{array}$ \\
\hline $\begin{array}{l}\text { ACR + Chrysin } \\
\text { (Therapeutic } \\
\text { group) } \\
\% \text { Change }\end{array}$ & $5.17 \pm 0.79^{\mathrm{abc}}$ & $64.05 \pm 2.47^{\mathrm{abc}}$ & $716 \pm 1.13^{\mathrm{abc}}$ & $9.55 \pm 1.48^{\mathrm{abc}}$ & $95.85 \pm 0.78^{\text {abcd }}$ \\
\hline
\end{tabular}

Each value represents mean $\pm \mathrm{SD},{ }^{\mathrm{a}}$ Significance $v s$. control group,${ }^{\mathrm{b}}$ Significance $v s$. ACR group,${ }^{\mathrm{c}}$ significant $v s$. chrysin ,

${ }^{\mathrm{d}}$ significant $v s$. chrysin + ACR group, ${ }^{\mathrm{e}}$ significant $v s$. ACR + chrysin group.

\section{Histopathological finding}

Histopathological examination of brain sections of control rats showed normal histological structure of brain tissue (Fig. 2 A). Animals administrated with acrylamide (ACR) showed a degeneration and nuclear pyknosis in the neurons of the cerebral cortex, atrophied hippocampus and focal area of eosinophilic plagues formation in the striatum (Fig. 2 B). In chyrsin treated rats; there was no histopathological alteration (Fig. 2 C). Rats administrated with chrysin and acrylamide (CHR+ACR) in parallel showed intact cerebral cortex, striatum with normal, while the hippocampus showed nuclear pyknosis in some of the neuronal cells and focal encephalomalacia was detected in striatum (Fig. 2 D), while rats administrated with acrylamide then chrysin (ACR+CHR) exhibited degeneration and nuclear pyknosis in the neurons of atrophied hippocampus (Fig. 2 E).

\section{Discussion}

Considerable experimental data from rodent studies have shown than ACR exposure produces pronounced neurotoxicity and that the oxidative stress in nervous tissue is linked to such neurotoxicity ${ }^{[13]}$. All these have converted ACR-neurotoxicity into a suitable experimental model to evaluate the potential intervention of new neuroprotective agents with antioxidant effects. Hence, the focus of the present work was to evaluate the effect of chrysin against ACRinduced neurotoxicity and the possible mechanisms underlined. The spontaneous formation of ACR during the cooking of food has led to its description as a cooking carcinogen ${ }^{[14]}$, in addition to the evidence of ACR mutagenicity; genotoxicity and carcinogenicity ${ }^{[15]}$ have also been reported. ACR therefore poses a potentially significant risk both for human and animal health. However, the mechanism by which ACR exposure causes cellular dysfunction in experimental animals and humans is not clear ${ }^{[16]}$.

In the current study, ACR significantly increased levels of MDA in the brain of rats. This might indicate that ACR might induce oxidative stress leading to lipid peroxidation. Consistently, a previous study showed that ACR and its metabolite glycidamide, enhance the production of reactive oxygen species (ROS) ${ }^{[17]}$. The oxidation of unsaturated fatty acids produces different compounds. MDA belongs to the secondary products and is used as a convenient marker for lipid peroxidation ${ }^{[18]}$. Noteworthy, lipid peroxidation play a significant role in neural system disorders including neurodegeneration. An increased MDA concentration was found in neurofibrillary tangles of Alzheimer's disease brains ${ }^{[19]}$. Similar data on MDA occurrence after exposure to ACR were presented by Zhu et al. ${ }^{[20]}$, Pennisi et al. ${ }^{[21]}$ and Mehri et al. ${ }^{[8]}$. This means that ACR has significant influence on redox balance in brain. Accordingly, several studies indicated that oxidative stress is a key mechanism in many ACR induced cell injuries and neurodegenerative diseases ${ }^{[22-23]}$. Consistently, a previous study showed that ACR is oxidized to glycidamide, a reactive epoxide, and undergoes conjugation with glutathione. DNA adducts from glycidamide have been reported following the administration of $\mathrm{ACR}{ }^{[24]}$.

Inflammation is a crucial factor in secondary damage after ACR exposure. It was reported that ACR could trigger the increased level of serum IL-6. The current 
study was in consistant with Zhao et al. ${ }^{[25]}$ and Ahmed and El-Menoufy ${ }^{[26]}$ who illustrated that the level of IL-6 was remarkably augmented in ACR-induced rats. The increased in MDA and IL-6 levels in the current investigation in ACR-treated rats might indicate the occurrence of inflammation and cell apoptosis. The administration chrysin suppressed the proinflammatory responses, which implicates the involvement of its antiinflammatory action in the attenuation of ACR in rats ${ }^{[27]}$. In neurons and astrocytes, ACR-induced apoptosis in a time- and dose-dependent manner markedly decreased the proliferation of neural progenitor cells, and in high concentrations induced apoptotic and necrotic cell death. Apoptosis was induced by a caspase-3-independent mechanism ${ }^{[28-29]}$. The caspases are the most important effector molecules in the execution of apoptosis and progression of the caspases cascade ending in the activation of caspase-3, the final mediator of apoptosis. Caspase-3 activity was increased in brain after ACR administration. ACR enhanced apoptosis in cerebral cortex through alteration of $\mathrm{Bcl}-2$ family protein expression. The elevation in caspase-3 activity upon ACR administration obtained results is related to the data of Seydi et al. ${ }^{[30]}$. In this study, caspase-3 level was induced in the ACR- treated groups while it was not induced in the group treated with ACR and chrysin together (Group 4). In accordance with our study, Elgholam et al. [31] reported that administration of chrysin decreased neuronal cell death via inhibition of apoptosis.

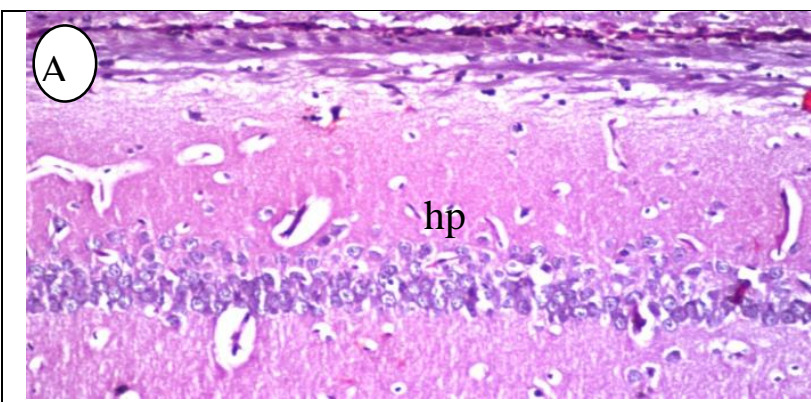

(A) Representative micrographs for the brain of rats in control (Group 1) showing normal histological structure of hippocampus (subiculum) $\mathrm{hp}=$ hippocampus.

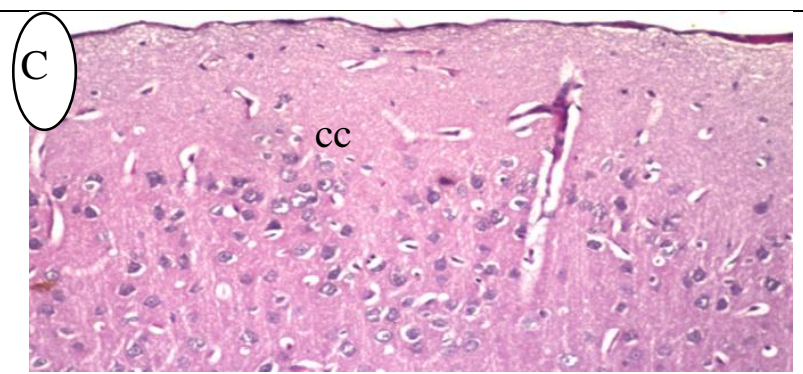

(C) Representative micrographs for the brain of rats in Group 3 showing normal histological structure of meninges' and neural cells in cerebral cortex. $\mathrm{m}=$ meningies, $\mathrm{cc}=$ cerebral cortex.

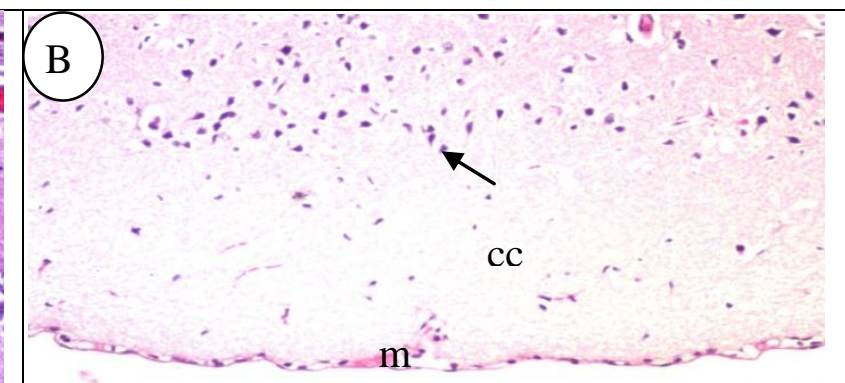

(B) Representative micrographs for the brain rats administrated acrylamide (Group 2). Picture showing nucleai pyknosis (arrow) in neurons of cerebral cortex. (Arrow = neucleai pyknosis)

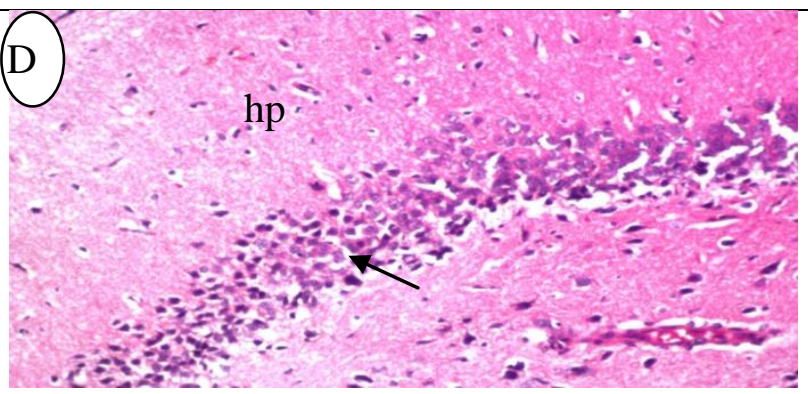

D) Rats administrated acrylamide and chrysin at same time (Group 4) showing nuleai pyknosis in neurons of hippocampus (arrow).

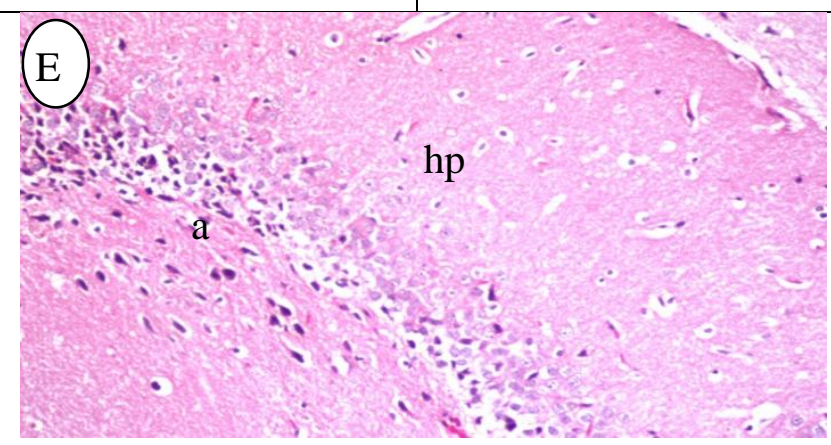

(E) Rats administrated acrylamide then chrysin (Group 5) showing nuleai pyknosis in some of neural cells with atrophy in hippocampus (hp) (a=atrophy).

Fig (2): Representative micrographs for the brain of all studied groups. 
In agreement with Aksenova et al. ${ }^{[32]}$ and Castegna et al. ${ }^{[33]}$ who observed that serum CK-BB activity was decreased in rats treated with $\mathrm{ACR}$, as shown in the present study. As the neurological dysfunction became less apparent after the end of giving acrylamide, the suppression of CK-BB activities in the brain became less obvious until it returned to normal when there was no neurological dysfunction [34]. Thus, inhibition of brain CK-BB seems to be the most sensitive indicator of acrylamide intoxication among the enzymes so far examined. The inhibition of activity of CK-BB in the brain might underlie the genesis of the neurotoxicity of acrylamide especially that of encephalopathy and it may be a good indicator of acrylamide intoxication ${ }^{[35]}$. The decrease in CK-BB activity was significantly modulated by chrysin administration.

Acetylcholinesterase is intimately associated with the normal neurotransmission by catalysing the hydrolysis of AChE to acetate and choline ${ }^{[35]}$. The present study indicated an increment in the activity of brain AChE in ACR-treated rats. In accordance, Pennisi et al. ${ }^{[36]}$ showed that ACR enhanced the activity of AChE in peripheral nerves. One of the most important mechanisms of ACR-induced cholinergic dysfunction is related to the ACR reaction with cysteine residues in the presynaptic membranes and inhibition of the neurotransmitter release into the synaptic cleft .However, there are other mechanisms influencing AChE activity. One of them may be related to direct binding of ACR and/or its metabolite glycidamide with active - SH sites of the AChE enzyme. The second one may be related to oxidation of the cysteine in the AChE enzyme by free radicals. Both mechanisms participate in AChE inhibition by acrylamide ${ }^{[37]}$. Oral administration of chrysin modulated the increasing activity of AchE.

Neurotrophins are chemicals that help to stimulate and control neurogenesis. Brain- derived neurotrophic factor is a member of the "neurotrophin" family of growth factors, which are related to the canonical "nerve growth factor', BDNF acts on certain neurons of the central nervous system and the peripheral nervous system, helping to support the survival of existing neurons, and encourage the growth and differentiation of new neurons and synapses. In the brain, BDNF is active in the hippocampus, cerebral cortex, and basal forebrain, areas vital to learning, memory, and higher thinking ${ }^{[38]}$. The brain-derived neurotrophic factor (BDNF) monitors synaptic function and plasticity, and is essential for neuronal growth and survival. $\beta$-amyloid accumulation can inhibit neurotrophic signaling. In the current study, BDNF signaling levels are significantly lower in ACRtreated rats, suggesting that loss or alterations in it may contribute to the pathogenesis of neuronal dysfunction in ACR administration and may be related to the high or toxic concentrations of the ACR. Chrysin administration modulates the decrease in BDNF level, which resulted in decreased $\beta$-amyloid production. This decrease may have been caused by inhibition of the $\beta$-Amyloid production pathway by BDNF-triggered responses, and further research is needed to elucidate this response ${ }^{[39]}$. The observation that ACR induced significant decrease in the levels of EPI, NE and Ser in treated rats probably indicated by the ACR induced common inhibition of monoaminergic neurotransmission. This might be interpreted by that ACR might inhibit monoamines synthesis and/or activate their degradation. In accordance, a previous study indicated that ACR increased the catalytic activity of monoamine oxidase in rat brain ${ }^{[40]}$. This might support that active degradation could cause a decrease in brain monoamine levels in ACR treated rats ,this depletion replenished after chrysin treatment.

\section{Conclusion}

Chrysin exhibited protective effects against ACRinduced neurotoxicity in Wistar rats through reduction of MDA, inflammatory marker; IL-6, AchE and $\beta$-amyloid $A$ associated with modulation of neurotransmitters, CK$\mathrm{BB}$ and BDNF. Concurrent supplementation of chrysin with ACR administration had a better effect than after ACR-exposure in both our histological findings and measured parameters.

\section{Acknowledgements:}

Thanks one due to Prof. Dr. Adel Bakeer Kholoussy Prof. of Pathology, Faculty of Veterinary Medicine. Cairo University, for writing the comments of the histopathological part of this work.

\section{References}

1) Al-serwi, R. H. and Ghoneim, F. M. (2015). The impact of vitamin $\mathrm{E}$ against acrylamide induced toxicity on skeletal muscles of adult male albino rat tongue; light of electron microscopic study. Journal of microscopy and ultrastructure, 137-147.

2) Friedman, M. (2003). Chemistry, biochemistry, and safety of acrylamide. a review J. Agric food chem., 30;51(16):4504-4526.

3) Shipp, A., Lawrance, G., Gentry, R., McDonald, T., Bartow, H., Bounds, J., Macdonald, N., Clewell, H., Allen, B. and Van Landingham, C. (2006). Acrylamide: review of toxicity data and dose-response analyses for cancer and noncancer effects. Crit. Rev. Toxicol., 36(6-7):481-608.

4) Seale, S. M., Feng, Q., Agarwal, A. K. and ELAlfy, A. T. (2012). Neurobehavioral and transcriptional effects of acrylamide in juvenile rats. Pharmacol Biochem Behav., 101(1):77-84.

5) Lopachin, R. M., Schwarcz, A. l., Gaughan, C. l., Mansukhani, S. and Das, S. (2004). In vivo and in vitro effects of acrylamide on synaptosomal neurotransmitter uptake and release. neurotoxicology., 25(3):349-363.

6) Rahangadale, S. I., Jangir, B. L., Patil, M., Verma, T., Bhandarkar, A., Sonkusale, P. and Kurkure, N. (2012). Evaluation of protective effect of vitamin e on acrylamide induced testicular toxicity in wister rats. Toxicol Int., 19(2):158-161.

7) LoPachin, R. M., Balaban, C. D. and Ross, J. F. (2003). Acrylamide axonopathy revisited. Toxicol. 
Appl. Pharmacol., 1; 188(3):135-153.

8) Mehri, S., Karami, H. V., Hassani, F. V. and Hossinazadeh, H. (2014). Chrysin reduced acrylamide-induced neurotoxicity in both in vitro and in vivo assessments. Iran Biomed J., 18(2):101106.

9) Yao, Y., Chen, L., Xiao, J., Wang, C., Jiang, W., Zhang, R. and Hao, J. (2014). Chrysin Protects against Focal Cerebral Ischemia/Reperfusion Injury in Mice through Attenuation of Oxidative Stress and Inflammation. Int J Mol Sci., 15(11): 20913-20926.

10) Yoshioka, T., Kawada, K., Shimada, T. and Mori, M. (1979). Lipid peroxidation in maternal and cord blood and protective mechanism against activated-oxygen toxicity in the blood. Am. J. Obstet. Gynecol., 135(3):372-376.

11) Ciarlone, A. E. (1976). A brief review of some properties of alpha-methylnorepinephrine. J Am Dent Assoc., 92(4):748-750.

12) Banchroft, J. D. Stevens, A. and Turner, D. R. (1996). Theory and practice of histological techniques. Fourth edition. Churchil Livingstone, New York, London, San Francisco, Tokyo. Bancroft, I., Fraser, F., Morgan, C., Trick, M. (2015).Collinearity analysis of Brassica A and C genomes based on an updated inferred unigene order. Data Brief., 10;3:51-5.

13) Menéndeza, R., Garcíaa, T., Garateixa, A., Moralesa, R. A., Regaladob, E. L., Lagunab A.,Valdésb, O. and Fernándeza, M. D. (2014). Neuroprotective and antioxidant effects of Thalassia testudinum extract BM-21, against acrylamideinduced neurotoxicity in mice. J. Pharm. Pharmacogn. Res., 2(3):53-62.

14) Alturfan, A. A., Tozan-Beceren, A., Sehirli, A. O., Demiralp, E., Sener, G. and Omurtag, G. Z. (2012). Resveratrol ameliorates oxidative DNA damage and protects against acrylamide-induced oxidative stress in rats. Mol Biol Rep., 39(4):45894596.

15) Hogervorst, J., Schouten, L. J., Konings, E. J., Goldbohm, R. A. and van den Brandt, P. A. (2007). Assessment of the relation between biomarkers for smoking and biomarkers for acrylamide exposure in humans. Cancer Epidemiol. Biomarkers Prev., 16: 2471.

16) Venkataswamy, M., Divya, K., Pallavi, C. and Thyagraju, K. (2013). Characterization of glutathione-s-transferases - suppression of antioxidant enzymes by acrylamide in developing chick embryonic brain. Int. J. Pharm. Bio. Sci., 4(3): $668-677$.

17) Ayala, A., Muñoz, M. F. and Argüelles, S. (2014). Lipid peroxidation: production, metabolism, and signaling mechanisms of malondialdehyde and 4hydroxy-2-nonenal. Oxid Med Cell Longev., 2014:360438.

18) Matveychuk, D., Dursun, S. M., Wood, P. L. and Baker, G. B. (2011). Reactive aldehydes and neuro- degenerative disorders. Klinik Psikofarmakol Bulteni. 21(4):277-288.

19) Arancibia, S., Silhol, M., Moulière, F., Meffre, J., Höllinger, I., Maurice, T. and Tapia-Arancibia, L. (2008). Protective effect of BDNF against betaamyloid induced neurotoxicity in vitro and in vivo in rats. Neurobiol. Dis., 31(3):316-326.

20) Zhu, Y. J., Zeng, T., Zhu, Y. B., Yu, S. F., Wang, Q. S., Zhang, L. P., Guo, X., Xie, K. Q. (2008). Effects of acrylamide on the nervous tissue antioxidant system and sciatic nerve electrophysiology in the rat. Neurochem Res., 33(11):2310-2317.

21) Pennisi, M., Malaguarnera, G., Puglisi, V., Vinciguerra, L., Vacante, M. and Malaguarnera, M. (2013). Neurotoxicity of acrylamide in exposed workers. Int J Environ Res Pub Health, 10:38433854.

22) Prasad, S. N. (2014). Mitigation of acrylamideinduced behavioral deficits, oxidative impairments and neurotoxicity by oral supplements of geraniol (a monoterpene) in a rat model. Chem. Biol. Interact., 5;223:27-37.

23) Santhanasabapathy, R., Vasudevan, S., Anupriya, K., Pabitha, R. and Sudhandiran, G. (2015). Farnesol quells oxidative stress, reactive gliosis and inflammation during acrylamide-induced neurotoxicity: Behavioral and biochemical evidence. Neuroscience, 12;308:212-227.

24) Ahmed, M. M., Farid, O. A. A. and Shehata, A. M. (2016). A Neuroprotective Role For Ferulic Acid Against Acrylamide -Induced Neurotoxicity In Rats. Journal of Global Biosciences., 5(2):3635-3644.

25) Zhao, M., Wang, P., Zhu, Y., Liu, X., Hu, X. and Chen, F. (2015). The chemoprotection of a blueberry anthocyanin extract against the acrylamide-induced oxidative stress in mitochondria: unequivocal evidence in mice liver. J Funct Food; 14: $95-101$.

26) Ahmed, M. M. and El-Menoufy, G. (2016). Ameliorative Effect of Ferulic Acid on Acrylamide Induced Inflammation and Oxidative Damage in Rat Testes. RJPBCS; 7(1).

27) Jiang, Y., Gong, F. L., Zhao, G. B. and Li, J. (2014). Chrysin suppressed inflammatory responses and the inducible nitric oxide synthase pathway after spinal cord injury in rats. Int. J. Mol. Sci., 15(7):12270-12279.

28) Ahmed, M. M., and El-Menoufy, G. (2016). Ameliorative Effect of Ferulic Acid on Acrylamide Induced Inflammation and Oxidative Damage in Rat Testes. Research Journal of Pharmaceutical, Biological and Chemical Sciences., 7(1).

29) Elmore, S. (2007). Apoptosis: a review of programmed cell death. Toxicol Pathol., 35(4):495516.

30) Seydi, E., Rajabi, M., Salimi, A. and Pourahmad, J. (2015). Involvement of mitochondrial-mediated 
caspase-3 activation and lysosomal labilization in acrylamide-induced liver toxicity. Toxicological \& Environmental Chemistry, 97(5):563-575.

31) Elgholam, M. A., Elbarbary, A. A., Zolfakar, A. S., Nooh, H. Z. and EL-mehi, A. E. (2015). The role of rosemary against acrylamide developmental toxicity on white matter of rat spinal cord. Menoufia Medical Journal, 28:765-773.

32) Aksenova, M. Y., Aksenovaa, M. V., Payneb, R. M., Smithc, C. D., Markesberyc, W. R. and Carneya, J. M. (1997). The Expression of Creatine Kinase Isoenzymes in Neocortex of Patients with Neurodegenerative Disorders: Alzheimer's and Pick's Disease. EL SEVIER J., 146:458-465.

33) Castegna A., Aksenov M., Aksenova M., Thongboonkerd V., Klein J. B., Pierce W. M., Booze R., Markesbery W. R. and Butterfield D. A. (2002). Proteomic identification of oxidatively modified proteins in alzheimer's disease brain. part $\mathrm{I}$ : creatine kinase $\mathrm{BB}$, glutamine synthase, and ubiquitin carboxy-terminal hydrolase L-1.EL SEVIER J., 33:562-571.

34) Boutet-Robinet, E., Trouche, D. and Canitrot, Y. (2013). Neutral comet assay. Bioprotocol., 3(18):e915 (http://www.bio-protocol.org/e915).

35) Matsuoka, M., Matsumura, H. and Igisu, $H$. (1996). Creatine kinase activities in brain and blood:possible neurotoxic indicator of acrylamide intoxication. Occup. Environ. Med., 53(7):468-471.

36) Pennisi, M., Malaguarnera, G., Puglisi, V., Vinciguerra, L., Vacante, M. and Malaguarnera, M. (2013). Neurotoxicity of acrylamide in exposed workers. Int J Environ Res Pub Health, 10:38433854.

37) Ahmed, M. M., Farid, O. A. A. and Shehata, A. M. (2016). A Neuroprotective role for ferulic acid against acrylamide-induced neurotoxicity in rats. Journal of Global Biosciences, 5(2):3635-3644.

38) Saleh, A. A. S. (2015). Anti-neuroinflamatory and antioxidant effects of acetyl cysteine in long term consumption of artificial sweetener aspartame in the rat cerebral cortex. The journal of basic \& applied zoology, 72:73-80.

39) Blurton-Jones, M., Kitazawa, M., MartinezCoria, H., Castello, N. A., Müller, F. J., Loring, J. F., Yamasaki, T. R., Poon, W. W., Green, K. N. and LaFerla, F. M. (2009). Neural stem cells improve cognition via BDNF in a transgenic model of Alzheimer disease. Proc. Natl. Acad. Sci. U S A., 11;106(32):13594-13599.

40) Arancibia, S., Silhol, M., Moulière, F., Meffre, J., Höllinger, I., Maurice, T. and Tapia-Arancibia, L. (2008). Protective effect of BDNF against betaamyloid induced neurotoxicity in vitro and in vivo in rats. Neurobiol. Dis., 31(3):316-326. 